\title{
Public transport as a social-legal phenomenon in the example of the city of Nizhnevartovsk (Khanty Mansi autonomous area Ugra)
}

\author{
V.A. Lez'er ${ }^{1}$, N.A. Semeryanova ${ }^{2}$, and $A . V$. Kopytova ${ }^{1 *}$ \\ ${ }^{1}$ Tyumen Industrial University, Volodarskogo str., 38, Tyumen, 625000, Russia \\ 2 Federal State Autonomous Educational Institution of Higher Education Yuzhno-Uralsky State \\ University, Mira str., 9, Nizhnevartovsk Branch, 628600, Russia
}

\begin{abstract}
The urgency of the problem under investigation is caused by the presence of contradictions that have arisen in the public and private regulation of relations in the provision of services to the population in the sphere of urban public transport and predetermines the need for coordinated legal regulation of transport relations, taking into account the specific functioning of public urban transport and its regional features. Such an approach will allow building public relations in the field of transportation in order to ensure not only effective regulation, but also its effective protection. Conclusions: In this connection, it is proposed to create a regional concept of transport development that takes into account the socio-economic characteristics of the region on the basis of monitoring of administrative-territorial units in order to identify priority areas and increase transport accessibility in every city in the region. Further improvement of the legislative regulation of this sphere will be futile without realizing that under current conditions the socio-economic and natural conditions of each particular region should be taken into account; it is simply necessary, as well as building parity between the population, the transport companies and the state.
\end{abstract}

\section{Introduction}

The relevance of the study is based on the need to optimize social interactions in the field of public transport, understood as a social and legal phenomenon of modernity. Public transport creates a field for the realization of the interests of various social groups that are integrated through consumption regulation or competing for ways of using socially important services. Participating in the organization of urban life, public transport is perceived as a benefit provided by a social state, but at the same time serves as a service to the population, and, therefore, is subject to legal assessment. In accordance with Articles 14-16 of the Law "On General Principles of the Organization of Local Self-Government in the Russian Federation" of 06.10.2003. № 131-FZ [1], creation of conditions for the provision of transport services and the organization of transport services are in the

\footnotetext{
*Corresponding author: a.copytowa@yandex.ru
} 
competence of municipalities and are assigned to issues of local importance. The provision of transportation services is based on the free operation of market mechanisms; the basis of these mechanisms is a healthy competition between transport companies engaged in profitmaking activities. However, the practice of functioning of public transport shows that the application of only private legal methods for regulating public relations arising in the transport sector is not enough. This activity is subject to significant restrictions and control by the state, which is carried out in the form of licensing. The purpose of state control is to prevent damage to the rights, legitimate interests and health of citizens, defense and security of the state, cultural heritage of the people of the Russian Federation. Despite public regulation, public transportation does not lose its private law nature based on civil law relations realized by the conclusion of relevant contracts and fully fall under private law regulation. The conflict of public and private interests predetermines the need for coordinated legal regulation of public transport. However, to date, an effective legal framework that adequately reflects the characteristics of public transport relations has not been formed. Legislation in force in this field is mostly obsolete. Regulation of transport relations for transportation should be built by creating a ramified system of legal norms that takes into account and regulates all aspects and specifics of the functioning of public transport, taking into account regional features. Such an approach will allow building public relations in the field of transportation that will be able to ensure not only effective regulation but also effective protection in the field of public transportation.

Private law relations are not confined to the framework of law, the everyday culture of public transport is a value system, the synthesis of formal rules and informal arrangements where the status interactions of consumers and transport service representatives are formed, discrimination practices are reproduced, values and norms of the passenger and driving community are formed, into action patterns. A legal analysis of these aspects is of considerable interest both for theoretical comprehension of social relations mediated by the transport sector and in the context of the applied tasks of improving transport services as an element of urban policy. Thus, it becomes obvious the importance of the legal factor in the study of the issue of satisfaction of the interests of consumers by various parameters of public transport.

Researchers conduct an assessment of the efficiency of urban transport (P. Bizyukov, E. Saveliev). There is a discussion on the appearance of municipal transport in interrelation with the urban space (V. Agroskin, G. Golts, P. Kuznetsov), the functioning of urban infrastructure and social sphere (V. Vagin, E. Danilova, O. Oberemko, H. Osadchaya).

Russian and foreign researchers devoted their studies to the complex study of urban public transport (B. Geronimus, A. Polyakov, V. Livshits, K. McConnell, S. Varian, etc.). [2] Issues of improving the management system and increasing the efficiency of the transportation process by urban public transport under severe weather conditions were investigated (N. Gerasimov, L. Reznik, A. Petrov). General problems of legal regulation in the sphere of urban public transport were considered (Gurzhei S.Yu., N. Fedorenko, S. Khaigetova).

The characteristics of interactions in the public transport system, the socio-cultural circumstances of the role of transport in the culture of the passenger and driver community in the urban environment, the culture of service and the citizens' satisfaction with its quality, as well as the socio-cultural content of the experience of transport mobility and the nature of the body control of work.

Imperfection and contradictions in the legal regulation lead to a decrease in the traffic safety and a deterioration in the level of transport services, which in turn causes so-called in the scientific community "transport fatigue" [3]. In addition, the construction of a wellcoordinated and efficient system of transportation in Russia is impossible without a single vector of nation-wide and regional development of the transport system. 
The aim of the research is to interpret the role of public transport as a phenomenon in the context of socio-cultural and legal relations in the space of a modern city; consider transport law as a branch of law; to reveal its branch belonging; to distinguish between public and private regulatory issues; to analyze the interrelation and correlation of federal and regional regulation of urban public transportations; Identify the problems of legal regulation affecting the decline in the quality of public urban transportation services.

In the conditions of social changes, there are created and broadcast ideas on the rules of interaction and values, patterns of behavior and the content of professional knowledge in the public transport system. The regulatory expectations for the provision and use of the transport service determine the perception of its quality and form a service culture.

The novelty of the research is the formulation, justification and solution of the tasks of examining urban public transport as a social and legal phenomenon; on the basis of the analysis of the problems of legal regulation of relations in the field of urban public transportation, it is proposed to create a "Regional Concept for Transport Development", taking into account the socio-economic characteristics of the region on the basis of monitoring the administrative territorial units in order to identify priority areas and increase transport accessibility in each city in the region. Further improvement of the legislative regulation of this sphere will be futile without realizing that under current conditions the socio-economic and natural conditions of each particular region should be taken into account; it is simply necessary, as well as building parity between the population, the carrier and the state.

Empirical basis was formed by semi-formalized interviews with passengers using transport services $(\mathrm{N}=11,2007-2008)$; The secondary analysis was subjected to the survey data "Passenger turnover by types of public transport" of the Federal Service of State Statistics $(\mathrm{N}=21718,1992-2007)$ and the Public Opinion Foundation $(\mathrm{N}=1000,2007$, 2008).

Federal Law No. 131-FZ of 06.10 .2003 (edited on 03.08.2018) "On the general principles of the organization of local self-government in the Russian Federation". Decree of the Government of the Russian Federation of December 20, 2017 No. 1596 (edited on 01.08.2018) "On approval of the state program of the Russian Federation "Development of the transport system" (2018-2021)". Decisions of the Supreme Court of the Russian Federation, judicial practice. Official statistics of local authorities in Nizhnevartovsk.

\section{Methods}

Summarizing the theories and methodological approaches to the problem of public transport and the space of sociocultural interaction existing in domestic and foreign sociology, the authors conceptualize and systematize the functioning of public transport as an object of sociological and legal research.

Theoretical views of J. Urry allow authors to address the issue of mobility, considered as the movement of human, material, information flows, which implies a wide variety of boundaries. In the focus are mobile communities of people who are imprisoned in the streams that constantly cross the borders of society, creating new time and space coordinates. Within the framework of I. Hoffman's interpretative approach, there is considered a trip in public transport, referred to a typical situation of urban everyday life, with significant aspects for the researcher (connected with the symbolic space of transport and public behavior). Based on V. Vakhshtein and I. Kopytoff, the representation of transport as a material object in its symbolic manifestation is realized. With reliance on the work of J.G. Mead, G. Garfinkel, J. Habermas social communication is considered, unfolding in public transport [1-23]. 
Public transport within the framework of social phenomenology is understood as an everyday reality, as a set of phenomena recreated by individuals in their awareness and interpretation of everyday life. Passenger flows of regularly moving individuals are defined in everyday culture as forming a market structure (demanded and consumed transportation services), collective experience with their rules and regulations that coordinate the behavior of people representing various urban groups. The space of movement, depending on the purpose, is divided into "pedestrian" and "transport". Transport is defined as a way of moving technical means and passenger masses.

Theoretical aspects of problems of legal regulation, considered by such authors as I. Strelnikova, V. Zhukov, V. Andreev allowed to recognize the complex character of transport law and its independence as a branch of law, delimiting from other industries, tracing the relationship between private and public regulation. Dialectical method allowed comprehensively investigating the nature of such contradictions.

Comparative legal method allowed correlating the federal legislation with the developing legislation of the region in the sphere of urban public transportation regulation, to reveal the discrepancy and shortcomings of the regional legislation.

The methods of implementing state objectives are ensuring proper legal regulation and creation of an effective Concept for the socio-economic development of urban public transport in the regions.

Transport is characterized as a commercial practice, containing elements of social policy, that gives the state the opportunity to provide goods for specific groups of citizens. One of the central positions where social policy measures are aimed is security. Within the limits of safety the author distinguishes three basic directions of actions on protection or liquidation of consequences of incident: the control of traffic safety on road pieces; protection from emergencies, control over the implementation of route trips and the recruitment of qualified drivers; material and psychological assistance in case of an accident. The second position, subject to political influence, is the physical condition of transport, that implies a competent schedule of flights, the convenience of the passenger compartment, the quality of the road surfaces, the uniform filling of the transport space (no crush), the attitude towards the passengers on the part of the service executors (driver, conductor) and moral comfort. Social policy renders the implementation of the service by establishing a standard introduced by federal and local authorities. The authors also take into account the importance of the legislation of the constituent entities of the Russian Federation, regulatory legal acts at the level of local self-government, considering the Ministry of Transport of the Russian Federation, implementing the state policy in the field of urban passenger transport, implementing a set of measures to maintain an acceptable level of passenger service provision for customers.

\section{Results}

In the Russian Federation, as in other developed countries, transport is one of the largest basic branches of the economy, the most important part of the industrial and social infrastructure. Transport creates the conditions for the planned development of all social production, concentration, cooperation and combining enterprises, deepening the territorial division of labor, and also links into a single system of the national economy. [4]

Building effective and optimal relations in the sphere of urban public transport is of paramount importance for the socio-economic development of the region and its transport system. Optimal solutions provide the maximum degree of achievement of the goal, ensuring efficient transportation to meet the needs of the population.

All decisions must lie in the plane of regional development programs. The concept of regional economic development is a system of measures aimed at realizing the long-term 
objectives of the country's social and economic development, taking into account the rational contribution of the regions to the solution of these tasks, determined by real prerequisites and constraints on their development. The concept can change depending on the socio-economic and political orientation of the state at a particular stage of development. In connection with this, the regulation of these relations is dynamic.

Each constituent entity of the Russian Federation independently determines the development strategy of its region, reflecting the specifics of territorial interests, and the program of actions should be oriented toward long-term goals. However, the construction of a coherent and efficient system of urban public transport is impossible without a single vector of nationwide and regional development of the transport system.

The main state and regional task should be to provide an efficient transport route network and accessibility of transport services for the population.

A necessary condition is the consistent implementation of the long-term state program for the development of the transport system in Russia. In this regard, in 2017, the Government of the Russian Federation adopted Decree No. 1596 of December 20, 2017 (edited on 01.08.2018) "On the approval of the state program of the Russian Federation "Development of the transport system" (2018-2021)".

The total amount of the Program financing is 7753331417,8 thousand rubles, including: 1867073636,3 thousand rubles in 2019; 1848709478.5 thousand rubles in 2020; 1970789446,4 thousand rubles in 2021.

The program defines the objectives of financing: 1 - acceleration of commodity circulation, reduction of transport intensity of the economy to 26.3 tons / km per 1000 rubles of gross domestic product. Transport capacity of the economy will be: in 2019 / 29.1 tons - km per 1000 rubles of gross domestic product; in $2020-28$ tons / km per 1,000 rubles of gross domestic product; in 2021 - 26.3 tons / km per 1000 rubles of gross domestic product; 2 - increasing the availability of high-quality transport services to ensure mobility of the population at the level of 4,2 thousand pass. / km per 1 inhabitant. Transport mobility of the population will make: in 2019 - 3,9 thousand pass. / km per 1 inhabitant; in 2020 - 4 thousand pass. / km per 1 inhabitant; in 2021 - 4.2 thousand passenger miles per 1 inhabitant; 3 - increase of competitiveness of the Russian transport system in the world market of transport services and growth of export of transport services to 19 billion US dollars. Export of transport services will make: in 2016 - 14,9 billion US dollars; in 2017 16.9 billion US dollars; in 2018 - 17.7 billion US dollars; in 2019 - 18.3 billion US dollars; in 2020 - 18.9 billion US dollars; in 2021 - 19 billion US dollars; 4 - improving the integrated sefety and sustainability of the transport system in order to reduce the number of transport incidents per vehicle unit by 10 percent compared to the level of 2016 . Such a reduction in the number of accidents in transport will be: in 2016 - 100 percent; in 2017 99 percent; in 2018 - 97 percent; in 2019 - 95 percent; in 2020 - 93 percent; in 2021 - 90 percent; 5 - decrease in the proportion of the road network of urban agglomerations operating in the regime of congestion in the "hour-peak", up to 68 percent. The proportion of the road network will reach 72 percent in 2019; in 2020 - 70 percent; in $2021-68$ percent. Directions of the program: Railways, Roads, Civil Aviation and Air Navigation Services, Marine and River Transport, Transport Supervision, Integrated Development of Transport Hubs, Ensuring the Implementation of the State Program of the Russian Federation On Development of the transport system. [5]

The previous Federal target program "Development of the Transport System of Russia (2010-2020)", approved by the Decree of the Government of the Russian Federation No. 848 of 05.12 .2001 (edited on May 15, 2014) is repealed.

Thus, the main factor is not the availability of resources, but the effectiveness of their use. The most effective tools for managing the economic development of the region at this stage are strategic planning and regional marketing. There is needed a provision of 
appropriate conditions for the development of urban public transport, that depends on the combined efforts of regional authorities and regional business in order to address pressing problems based on self-regulation of business entities.

In this regard, the methods of implementing state objectives include ensuring proper legal regulation and the creation of an effective Concept for the socioeconomic development of urban public transport in the West Siberian region.

On the basis of their thesis about the complex legal regulation of transport relations, we can conclude that the problem of urban transport and public transport are complex, i.e., lie in the different branches of law, namely:

1) in the failure of transport organizations to fulfill their contractual obligations for various reasons, including those related to traffic congestion (a national task that should include not only the unloading of urban road networks operating in the regime of congestion in the hour-peak, but also take into account the interregional traffic congestion). This will reduce the risks associated with urban public transportation, and the citizens, in conditions of severe climate, will not freeze waiting for public transport for a long time, as well as go to crowded buses;

2) standards and regulations in the area of public urban transportation by municipal transport companies of the city are mostly respected, unlike the city's route transport, that carries out transportation on a commercial basis. As a rule, elementary sanitary measures on cleanliness are not observed in salons of such vehicles, there is a dirt, drivers accept for transportation the quantity of people not supposed by specifications. Route transport should be constantly adjusted; this is due to the numerous current changes in the resettlement of residents, the change in the location of places of employment, the modernization of the city's road network;

3 ) the reduction of the risk of road accidents is needed (a national task that provides for an increase in the complex safety and stability of the transport system in order to reduce the number of accidents in transport). Based on their Supreme Court decisions, all risks of loss of cargo lie on the professional driver who "can not know about the risks associated with road accidents" and such "force majeure" circumstances are not applied to such drivers; [6]

4) certain problematic issues of payment and taxation. For example, the analysis of judicial practice allows us to establish that the legal norms do not provide for the unconditional duty of the carrier to carry all groups of passengers in public transport for free, this duty arises only if the costs incurred by the transport company in this connection are compensated from the regional budget on the basis of the contract concluded with the transport company. [7] And the cost of tickets for city public transport for employees performing official trips in the interests of the employer, personal income tax is not assessed. [8]

5) lack of effective control by the state of the subsidies provided, which often leads to abuses of transport organizations, etc.

In this regard, it is proposed to monitor the territories of regions in order to identify priority areas and increase the transport accessibility of regions for citizens, to develop the concept of regional transport development, taking into account the socio-economic characteristics of the regions, the main goal of which will be to achieve a balance of interests of the population, the transport company and the state.

Relations that develop in the process of transport activities are diverse. They are of great importance for the state as a whole and equally important for the regions, and therefore need effective state regulation, which is ensured by creating a ramified system of rules of law that take into account and regulate all aspects and specifics of the functioning of transport, including urban areas public transportation. [9]

On the example of the city of Tyumen, one can say that here public transport is poorly developed, and it is inconvenient to use it. Electric transport does not exist at all, there used 
to be a trolleybus, but in 2009 it was destroyed. The contact network was dismantled, and the trolley buses were sent to Kurgan, where they traveled until 2016, when the Kurgan trolleybus was also destroyed. The main park is diesel buses. Like in most cities of Russia, along with large buses, small ones travel, and along with municipal buses, private ones. By the way, one diesel bus (in Tyumen it is mainly MAZ and LiAZ) emits as much harmful substances into the atmosphere during 12 years of operation as 27 cars in the same period.

According to official data of local authorities public bus transportations are carried out by eight transport enterprises in 2016 in Nizhnevartovsk. [10] The presented table clearly demonstrates the present state of public urban transport with $80-90 \%$ wear of vehicles.

Providing the movement of people and thereby the functioning of the systems of employment, education, social sphere, public transport in Western Siberia is the most important status-role complex of the social system, an orderly value-normative structure, regulates the rules of interaction and norms of socio-cultural relations. There is an update of the formal principles of behavior, socio-cultural representations are being reformed, the order of operation of such mechanisms as the timetable, the queue, the distribution of places, the ways of communication of key agents is changing. The schedule serves to regulate the inner city space and time, where time is a measurable expression of administrative power, and transport routes and wagons are areas of its application.

The culture of service on urban public transport in Tyumen and Nizhnevartovsk, as well as the daily practices of the behavior of passengers, drivers and conductors, implies acquired values and role expectations, which encourage agents to observe the rules that are appropriate for their status. The concept of quality is correlated with the normative image of a service, which implementation standard should ideally be shared by all participants in the process. In reality, shortage of personnel and material base, as well as high standards of business and professional ethics, as analysis has shown, leads to a decrease in the quality of services, and the level of passenger satisfaction is rather low in terms of availability, comfort, optimal time intensity and spatial saturation.

The results of the research can contribute to more rational and effective regulation of urban public transport in the regions, as well as the creation of favorable conditions.

\section{Discussion}

Transport Law of Russia has a number of serious problems of a doctrinal and practical nature. In science, the question of the sectoral nature of transport law is debatable. Some authors consider transport law as an independent branch of law; others recognize its types as separate branches (air, sea, land, automobile, etc.). There was no common opinion on the question what sphere of law it is necessary to refer to, private or complex. Thus, some authors define transport law as civil law; others recognize it as an integrated branch of law (V. Zhukov, S. Aseev, V. Baukin, etc.). Supporting the position of V. Grechuha, V. Andreev, I. Strelnikova, [11] we agree that the transport law is a complex branch of law in the sphere of organization and carrying out of transportations, including civil-law relations, labor and procedural relations, administrative relations in matters of monitoring compliance with the rules of using transport as a source of increased danger. The question remains of the need for an operating licensing institute in the conduct of transportation. Supporters of licensing consider the state as a regulator of the requirements and conditions necessary for compliance by business entities in the transport sector (E. Gubin). Others see this as a means of restraint and interference in private legal relationships (V. Popondopulo, V. Mamutov). [12] Confusion in doctrinal issues leads to a violation of the balance of regulation of this sphere of legal relations and entails problems of law enforcement, including in urban public transportation. 


\section{Conclusion}

At present, building effective and optimal relations in the sphere of regional urban public transport is of paramount importance for the development of the transport industry and other branches of the economy in Russia. Optimal solutions provide the maximum degree of achievement of the goal, ensuring efficient transportation to meet the needs of the population and business. However, the lack of an effective concept of urban economic development in the sphere of public urban transport does not allow building harmonious relations in the provision of this type of services. The conceptual system of measures should be aimed at realizing the long-term objectives of the social and economic development of cities, taking into account the rational contribution of the regions, the Tyumen Region and the Khanty-Mansiysk Autonomous Area Ugra to the solution of these tasks, determined by the real prerequisites and limitations of their development. Of course, the Concept can change depending on the socio-economic and political orientation of the state at a particular stage of development, so this concept should be dynamic. In turn, building of a well-coordinated and efficient system of transportation in Russia is impossible without a single vector of nation-wide and regional development of the transport system. In this connection, the reasons for underdeveloped relations in the sphere of urban public transport are seen in the weak regional and federal interaction. In this regard, it is proposed to monitor the territories of regions in order to identify priority areas and increase the transport accessibility of regions for citizens.

Transport trips, in addition to comfort, carry risks and discomfort. Subjective images of the routes made by users of public transport reflect the surrounding reality with sensible meanings recognized by environmental objects, where significant elements appear, differing in convenience or discomfort, availability or presence of barriers. The established transport routes are criticized from the standpoint of the interests of specific consumers due to the absence of stops near important health and social protection points, leisure infrastructure and cultural sites. In rare cases, the mechanisms of sewerage are criticized by consumers in hot lines of communication with the provider and consolidated statements by citizens. By providing opportunities for mobility in conditions of mass consumption, the vehicle becomes a public place for exercising power, producing everyday symbolic classifications, a space open to social interactions and mutual typification. The time parameters of the individual privileged good are defined here as common with the group for the period of travel in one vehicle. Subjective practices of addressing the transport service are formed against the backdrop of individual social knowledge that constitutes the experience of the passenger community. Acting as a special value in deficit conditions, the transport space becomes the reason for the resource competition, stipulating the peculiarities of the practices of the interim community, the rules for the distribution and zoning of the internal space, generating a synthesis of people's knowledge and tactics of actors in everyday drama. By the implementation of everyday social experience, a special role is played by the aspect of corporeality, implying special norms of behavior based on the categorization of risks and ways to minimize them.

The results of the research are important for the implementation of legal analysis of the structure of the functioning of public transport in urban reality, critical consideration of the forms of state social policy in the sphere of passenger transportation, aimed at protecting customers and increasing the availability of services.

\section{Acknowledgments}

The work was supported by Act 211 of Government of the Russian Federation, contract No 02. A03. 21. 0011. 


\section{References}

1. Russian Federal Law No. 131-FZ (2003) (as amended on 08/03/2018)

2. URL: www.dissercat.com/ [date of circulation 18.09.2018]

3. N.A. Dubova, In the collection. sci. works: on the basis of the X-th Congress of ethnographers and anthropologists of Russia. (Moscow, Institute of Ethnology and Anthropology, 2013)

4. URL: http://mf.npitu.ru/ [circulation date. September 10, 2018]

5. Decree of the Government of the Russian Federation of December 20, 2017 No. 1596 (as amended on 01.08.2018)

6. Review of court practice in disputes related to contracts for the carriage of goods and transport expeditions, Presidium of the Supreme Court of the RF on 20.12.2017

7. Encyclopedia of judicial practice. Shipping. The freight charge (Article 217 of the Tax Code) (2018)

8. V.F. Popondopulo, Commercial (entrepreneurial) law school (Moscow, Norma, 2008)

9. M. Lezier, A. Gusarova, A. Kopytova, IOP Conference Series: Earth and Environmental Science, 90 (1), 012034 (2017) DOI: 10.1088/1755-1315/90/1/012034

10. N. Zotkina, A. Kopytova, M. Zenkina, O. Zhigunova, MATEC Web of Conferences, 106, 08058 (2017) DOI: 10.1051/matecconf/201710608058

11. VK Andreev Transport Law: Textbook. Allowance ( Kalinin, 1977)

12. A.V. Kopytova, Exchange of intellectual property 3 (XIV), 31-37 (2015)

13. V. Lezier, M. Gusarova, A. Kopytova, IOP Conference Series: Earth and Environmental Science, 90 (1), 012069 (2017) DOI: 10.1088/1755-1315/90/1/012069

14. N.V.Sorokina Professionalization of social management. (Saratov, Scientific Book, 2008)

15. A. Kopytova, Procedia Engineering 165, 1132 (2016) DOI: 10.1016/j.proeng.2016.11.830

16. K. Pykhtin, T. Simankina, V. Sharmanov, A. Kopytova, IOP Conference Series: Earth and Environmental Science, 90 (1), 012065 (2017) DOI: 10.1088/17551315/90/1/012065

17. V.G. Baukin, Railway transport law in the system of Russian law (Khabarovsk, 2007)

18. N. Zotkina, S. Bardasov, M. Gusarova, A. Kopytova, MATEC Web of Conferences, 106, 08050 (2017) DOI: 10.1051/matecconf/201710608050

19. Fedorov, M., Matys, E., Kopytova, A. E3S Web of Conferences, 33, 03054 (2018) DOI: $10.1051 / \mathrm{e} 3$ sconf $/ 20183303054$

20. V.N. Grechukha, Transport Law of Russia: a textbook for acad. Baccalaureate (Moscow: Yurayt Publishing House, 2018)

21. M. Gravit, O. Zybina, A. Vaititckii, A. Kopytova, IOP Conference Series: Earth and Environmental Science, 90 (1), 012103 (2017) DOI: 10.1088/1755-1315/90/1/012103

22. Kopytova, MATEC Web of Conferences, 106, 08056 (2017) DOI: 10.1051/matecconf/201710608056

23. S.V. Aseev, Transport Law. Special part: Textbook. Allowance (N. Novgorod, 2007) 